\title{
PROBLEMATIZAÇÃO DA AZIA NO ENSINO DE QUÍMICA: MOBILIZANDO CONHECIMENTOS PARA O EQUÍLIBRIO QUIMICO
}

\section{ALEX RODRIGUES}

Instituto Federal Catarinense (IFC) - Campus Araquari

E-mail: chemicaalex@gmail.com

\section{ANELISE GRÜNFELD DE LUCA}

Instituto Federal Catarinense (IFC) - Campus Araquari

E-mail: anelise.luca@ifc.edu.br

\section{RESUMO}

Este trabalho objetiva apresentar os resultados obtidos a partir do desenvolvimento de uma sequência didática que teve como tema a problematização da azia no ensino de química, sendo resultado do Estágio Supervisionado do curso de Licenciatura em Química do Instituto Federal Catarinense, tendo como público 29 estudantes do 2 o ano do ensino médio de uma escola pública da região norte de Santa Catarina. Os dados coletados se deram por meio da aplicação de um questionário diagnóstico, da participação na discussão oportunizada durante as aulas e nas atividades experimentais e na escrita de um texto. Para a análise dos dados foram considerados os pressupostos de aprendizagem apresentados por Moraes, Ramos e Galiazzi (2007): aprender como reconstruir o já conhecido; aprender como movimentar-se na linguagem; fala, escrita e leitura como ferramentas do aprender; ressignificação da experimentação em química a partir a linguagem. A partir da discussão dos dados coletados é possível perceber evidências de aprendizagens em diversos momentos: na interação, nos questionamentos dos conteúdos, nos momentos dos experimentos demonstrativos, configurando que esta temática problematizou e mobilizou vários saberes e conhecimentos no e para o ensino de química.

\section{PalaVRas-ChaVe:}

Ensino por Problematização; Azia; Ensino de Química; Práticas Pedagógicas.

PROBLEMATIZATION OF HEARTBURN IN CHEMISTRY TEACHING: MOBILIZING KNOWLEDGE FOR CHEMICAL BALANCE

\section{ABSTRACT}

This work aims to present the results obtained from the development of a didactic sequence that had as its theme the problematization of heartburn in chemistry teaching, because of the Supervised Internship of the Chemistry Degree course at the Instituto Federal Catarinense, with 29 students from 2nd year of high school at a public school in the northern region of Santa Catarina. The collected data were given through the application of a diagnostic questionnaire, participation in the discussion offered during classes and in experimental activities and in the writing of a text. For data analysis, the learning assumptions presented by Moraes, Ramos and Galiazzi (2007) were considered: learning how to reconstruct what is already known; learn how to move in language; speaking, writing and reading as learning tools; resignification of experimentation in chemistry from language. From the 
discussion of the collected data, it is possible to see evidence of learning at different times: in the interaction, in the questioning of the content, in the moments of demonstrative experiments, configuring that this theme problematized and mobilized various knowledge and knowledge in and for the teaching of chemistry.

\section{KEYWORDS:}

Problematization Teaching; Heartburn; Teaching Chemistry; Pedagogical practices.

\section{INTRODUÇÃO}

O ensino de química desenvolvido no ensino médio na maioria das escolas ainda enfatiza a transmissão de conteúdos e a memorização de fatos, símbolos, nomes, fórmulas, atribuindo importância a provas padronizadas, deixando de lado a construção do conhecimento científico, gerando a desvinculação entre o conhecimento químico e os conhecimentos prévios dos estudantes (SCHNETZLER; ARAGÃO, 1995)

Diante destas prerrogativas é importante considerar a necessária renovação do Ensino de Ciências (CACHAPUZ et al, 2005), buscando metodologias diferenciadas, viabilizando a aprendizagem, favorecendo os saberes que o estudante traz da sua cultura e das suas vivências (CHASSOT, 2008).

$\mathrm{Na}$ intenção de uma educação voltada para alfabetização científica e tecnológica, é relevante considerar as proposições de Fourez e Rouanet (1995) quando apresenta que a escolha, a definição tecnológica não são meios neutros, e sim a escolha de modelos de sociedade, considerando que a tecnologia incorpora, materializa interesses e características de sociedades ou de grupos sociais hegemônicos. Também se deve atentar para o que Chassot (2003, p. 91) afirma "a ciência como uma linguagem; consequentemente ser alfabetizado cientificamente é saber ler a linguagem em que está escrita a natureza. É um analfabeto científico aquele incapaz de uma leitura do universo". 
No intuito de utilizar situações problematizadoras, que fomentem os saberes populares, emergidos do cotidiano dos estudantes, defende-se aqui que o termo "problema" se aproxima de uma

situação nova que condiciona a criatividade a desenvolver estratégias e tomar decisões, situações que gerem conflitos e incertezas, que mobilizem maneiras e condutas visando a sua resolução, essas situações que tendem esse equilíbrio se definem como problemas (GONÇALVES; MOSQUERA; SEGURA, 2007, p. 9).

Assim as situações problematizadoras têm como finalidade relacionar a química com o cotidiano, considerando que os fenômenos que ocorrem na vida dos indivíduos devam ser problematizados em sala de aula, DELIZOICOV; ANGOTTI (1990), SANTOS; MORTIMER (2001). O cotidiano neste aspecto é pensado não como um modismo, que segundo Chassot (2003) teria o simples propósito de ensinar somente os conceitos científicos, mas o que se defende é o cotidiano para além do conceitual, estudar também possíveis implicações sociais, ambientais e políticas, ou seja, fazer emergir o contexto de implicações que envolvem esta problemática no dia a dia das pessoas.

Cabe ao professor democratizar os conhecimentos científicos como argumentam Santos e Mortimer (2001, p.107) "[...] se desejarmos preparar os estudantes para participar ativamente das decisões da sociedade, precisamos ir além do ensino conceitual, em direção a uma educação voltada para a ação social responsável". Neste sentido é preciso pensar o ensino de química para além do conceitual; poder-se-ia vislumbrar problematizações envolvendo o contexto de vivência dos estudantes, situações reais, que podem ser discutidas e nas quais os estudantes têm algo a dizer, como participantes da vida.

Contudo às desconexões entre os saberes populares, escolares e científicos, provocam a despreocupação por estabelecer relação entre ideias e realidade, educador e educando, teoria e ação, promovendo-se assim a despersonalização do processo pedagógico. Esta prática não leva em consideração as relações entre os 
conteúdos e as situações vivenciadas pelo estudante, desprezando a sua contextualização.

Este trabalho tem como objetivo apresentar e discutir os entendimentos sobre os conceitos químicos que os estudantes manifestaram durante o desenvolvimento de uma sequência didática, que problematizou o tema azia. A questão problema orientadora foi: De que maneira os estudantes do 2o ano do Ensino Médio se apropriaram dos conceitos referentes ao equilíbrio químico (reações reversíveis e irreversíveis, constante de equilíbrio da água, comportamento ácidos e bases das substâncias aquosas, pH e pOH) por meio da abordagem do tema azia?

\section{METOdOLOGIA}

A sequência didática foi desenvolvida em uma turma de 29 estudantes do 20 ano do ensino médio de uma Escola Pública de Joinville - SC, totalizando 8 aulas de 45 minutos, utilizando como procedimento metodológico, os três momentos pedagógicos, sistematizados por Delizoicov e Angotti (1990), em Freire (1987) e Snyders (1988): problematização inicial, organização do conhecimento e aplicação do conhecimento.

No primeiro momento: "Problematização Inicial", foi aplicado um questionário como forma de coletar dados, identificando os entendimentos dos estudantes para promover debates sobre o tema azia. Os questionamentos propostos estão apresentados na figura 1 .

Figura 1: Questionário diagnóstico aplicado aos estudantes. Fonte: Dos autores, 2017.
1) Você já sentiu ou presenciou alguém se queixando de queimação no estômago?
( ) $\operatorname{sim}$ ( ) não
2) Você conhece ou ouviu falar sobre azia?
( ) $\operatorname{sim}($ ) não
3) Já parou para pensar de que forma esse mal-estar acontece no organismo?
( ) $\operatorname{sim}($ ) não
4)Acredita que a sua alimentação pode de alguma forma favorecer esse mal-estar?
( ) $\operatorname{sim}($ ) não 
5) Você conhece algum procedimento que alivia este mal-estar?

Na sequência foi realizada a leitura de um texto intitulado: "Contra a química, não há azia que resista" (PEREIRA, 2004), com o intuito de proporcionar discussões sobre a relação entre azia e os conceitos químicos relacionados ao equilíbrio químico. Ainda foi realizado um experimento denominado "Sopro Mágico", que consistiu em uma solução básica de cor rósea, indicado pela utilização da fenolftaleína, com a inserção de gás carbônico provindo do sopro, a solução ficou transparente devido à formação do ácido carbônico.

No segundo momento: "Organização do conhecimento", foram apresentados os conteúdos referentes ao equilíbrio químico (reações reversíveis e irreversíveis, princípio de Le Chatelier e os fatores que influenciam o equilíbrio químico nas reações) com auxílio de um experimento demonstrativo sobre o aquecimento do sulfato de cobre. Esse experimento suscitou a discussão dos conceitos químicos relacionados ao equilíbrio químico.

Em seguida foram explicitados os conceitos: $\mathrm{pH}$ e pOH, equilibro iônico da água; solução tampão; ácidos e bases na linguagem cotidiana; ácidos e bases comportamento químico na água; após foi realizado outro experimento de escala de $\mathrm{pH}$, no qual os estudantes puderam visualizar os valores de $\mathrm{pH}$ de produtos e alimentos utilizados em seu dia a dia.

No terceiro momento: "Aplicação do conhecimento", foram retomadas as questões propostas no primeiro momento, com a escrita de um texto no qual o estudante relatou a importância do ensino de química proposto, com o objetivo de confrontar os conhecimentos iniciais com os conhecimentos adquiridos a partir da sequência didática explicitada. 
$\mathrm{Na}$ intenção de elucidar questões ligadas diretamente à fisiologia do organismo foram respondidos os questionamentos: se a azia é um desequilíbrio químico, qual a importância da alimentação para manter esse equilíbrio? De que maneira os conhecimentos químicos podem contribuir para evitar esse mal-estar? Tendo como fundamento essas perguntas ocorreu uma discussão sobre como ocorre a azia e as formas de prevenção. Ainda foi organizada uma roda de conversa sobre os conceitos químicos estudados, com a finalidade de demonstrar para os estudantes como estes conhecimentos se fazem presentes em seu dia a dia.

\section{RESUlTAdOS E DisCUSSÃO}

A análise dos resultados obtidos por meio da sequência didática considerou os pressupostos de aprendizagem apresentados por Moraes, Ramos e Galiazzi (2007): aprender como reconstruir o já conhecido; aprender como movimentar-se na linguagem; fala, escrita e leitura como ferramentas do aprender; ressignificação da experimentação em química a partir a linguagem.

Acredita-se que mediante a análise dos dados obtidos nesta intervenção pedagógica se possa atingir o objetivo proposto e buscar respostas para a questão que orientou este trabalho: De que maneira os estudantes do $2 \stackrel{0}{ }$ ano do Ensino Médio se apropriaram dos conceitos referentes ao equilíbrio químico por meio da abordagem da azia?

Nesta intenção foi possível delimitar quatro categorias de análises. Primeiramente se discutirá a aprendizagem como algo que se reconstrói a partir do conhecido, os dados analisados versam sobre as respostas do questionário diagnóstico. A segunda categoria a aprendizagem como um movimento da linguagem, foi compreendida a partir das falas dos estudantes quando explicitaram conceitos apropriados por eles. Na sequência, a aprendizagem como uma dinâmica da fala, da escrita e da leitura, visa discutir as possibilidades que o texto: "Contra a química, não 
há azia que resista" (PEREIRA, 2004), proporcionou em relação as aprendizagens dos conteúdos de química considerando o tema azia. Por último a experimentação ressignificada por meio da linguagem, busca-se entender as contribuições da experimentação para as compreensões dos conceitos químicos e sua inter-relação com o tema azia.

\subsection{AprendizAgem COMo Algo qUe Se ReCOnStról a PARTIR do ConheCIDO}

A aprendizagem se dá a partir das concepções prévias, considerando as ideias e explicações dos estudantes, é o ponto de partida. Assim as respostas obtidas no questionário diagnóstico possibilitaram perceber os conhecimentos dos estudantes sobre azia. Quando questionados se já haviam sentido ou presenciado alguém se queixando de queimação no estomago, todos responderam positivamente. Isso também foi constatado na questão 2, quando observamos que o estudante tem conhecimento ou ouviu falar sobre azia. Na questão 3 os estudantes foram questionados se de alguma forma pensaram como a azia acontecia, a totalidade respondeu não, contribuindo para o desenvolvimento da sequência didática. Já a questão 4 indagou aos estudantes se a sua alimentação poderia provocar azia, e todos responderam sim; e pôr fim a última pergunta questionava se eles conheciam algo que aliviava esse mal-estar, as respostas variaram entre antiácidos e remédios caseiros.

A partir disso pode se afirmar que o tema proposto é conhecido pelos estudantes, pois de alguma forma já o vivenciaram e está presente no seu cotidiano. Esses conhecimentos anunciados por eles serviram como ancoragem para as novas proposições apresentadas e discutidas no transcorrer da sequência didática. Moraes, Ramos e Galiazzi, (2007, p. 192) explicitam que "[...] um aprender significativo solicita uma ancoragem do já conhecido que os estudantes trazem para a sala de aula [...]". Ainda enfatizam que "[...] a apropriação e construção do conteúdo de [...] química nos 
significados cotidianos já anteriormente construídos pelos estudantes é, em essência, o que constitui aprender química [...]".

Em resposta a questão: de que forma a aula de química pode ajudar você a compreender melhor a azia? As respostas dos estudantes apresentaram explicações e apropriação de conceitos, conforme as falas dos estudantes E1, E2 e E3.

"A azia pode ser contida apenas tomando um antiácido que transforma o ácido clorídrico presente no estomago em ácido carbônico mais fraco" (E1).

"Saber que nosso estomago tem um ácido forte e que isso é controlado devido a nossa alimentação e quando não se pode controlar o excesso pode causar azia". (E2).

"O que contribui para a azia é a alimentação, por isso uma dieta balanceada de alimentos com potencial ácidos e básicos fará bem a saúde”. (E3).

É possível perceber que os termos científicos/conceitos, destacados em negrito, discutidos nas aulas de química foram utilizados na resposta dos estudantes, demonstrando que houve aprendizagem e apropriação dos conhecimentos/conceitos da química, como: "antiácido", identificação dos ácidos presentes na reação que provoca a azia no estomago: ácido clorídrico (E1). Destaca-se também a relação entre alimentação e azia que o estudante E2 expõe na resposta e outra vez o termo ácido é citado, evidenciando um saber daquilo que está presente na sua vida. Ao citar uma alimentação equilibrada o estudante E3 relaciona a azia com a alimentação e alerta para uma alimentação balanceada composta por alimentos com potenciais ácidos e básicos.

\subsection{Aprendizagem Como Movimento de Linguagem}

A sequência didática proporcionou momentos ímpares que foram além dos muros da escola, revelando as conversas em casa, com seus familiares, e a discussão sobre aquilo que se aprende em sala de aula, conforme os recortes retirados de um texto escrito pelos estudantes E4, E5 e E6. 
"Conversei com meus pais falei com eles do pH, é ácido as bebidas coca cola, guaraná, refrigerantes devido na sua produção adicionar ácidos fosfóricos, ascórbicos" (E4).

"A café bebida mais tomada no Brasil causa azia, pois tem característica ácida." (E5).

"O chocolate que gosta tanto também esta lista de alimentos que causam azia, foi dito na aula que ele contém cafeína e ácido oxálico." (E7).

A linguagem utilizada nas escritas de E4, E5 e E6 demonstram a apropriação do termo "ácido" pelos estudantes, quando explicam a ação de algumas substâncias presentes em bebidas conhecidas. Isto corrobora com que Moraes, Ramos e Galiazzi, (2007, p.195) afirmam: "[...] a partir do momento que expressamos os significados mais complexos e abrangentes demonstramos nossas verdadeiras aprendizagens".

\subsection{AprendizAgem como DinÂMICA dA Fala, dA Escrita e dA LeITURA}

A leitura do texto intitulado "Contra a química, não há azia que resista" (PEREIRA, 2004), favoreceu a discussão sobre o tema azia. Moraes, Ramos e Galiazzi, (2007, p. 199) afirmam que "a leitura ajuda a criar espaços de interação com uma comunidade de especialistas nos diferentes temas". As discussões proporcionadas por meio do texto lido "movimentou" a importância de cuidar da alimentação, pois muitos alimentos podem provocar azia, isto está evidenciado nas respostas E7, E8, E9 e E10. É possível identificar nas escritas destes estudantes, entendimentos sobre o tema.

"A azia é causada pelo excesso de ácido clorídrico que está no estomago, quando comemos alimentos com comportamento ácidos isso ajuda a queimação aumentar" (E7).

"Uma arma contra a azia é ingerimos uma base ou antiácido sal de fruta que neutralizará a força do ácido, proporcionado o equilíbrio no organismo." (E8).

"O equilíbrio iônico é o responsável pela neutralização do ácido e excesso no estomago, usando uma base formando um sal e água." (E9).

"A alimentação é o responsável pela causa da azia, por isso entender a composição de alguns alimentos e seus comportamentos ácidos e básicos é muito importante." (E10). 
As discussões sobre a azia fomentaram a escrita de um texto na busca de explicitar os conceitos apropriados pelos estudantes. Segundo Moraes, Ramos e Galiazzi, (2007, p. 201) "ao escreverem, os estudantes necessitam expressar seu pensamento enquanto os produzem [...] e ainda [...] pensar na aprendizagem da química que se dá por envolvimento dos estudantes em pensar, elaborar hipóteses, argumentar, descrever, interpretar".

\subsection{A EXPERIMENTAÇÃO RESSIGNIFICADA POR MEIO DA LINGUAGEM}

A utilização de experimentos na sequência didática objetivou observar por meio das reações químicas os conceitos químicos relacionados com o equilíbrio químico. Para isso foram realizados três experimentos intitulados: sopro mágico que apresenta o equilíbrio das reações ácidos e bases, o aquecimento do sulfato de cobre penta hidratado que demonstra a reversibilidades das reações químicas e a construção de uma escala de $\mathrm{pH}$ e pOH com alimentos e alguns produtos de limpeza doméstica escolhidos pelos estudantes. Após a realização dos experimentos os estudantes elaboraram um relatório, onde foi possível identificar as explicações dos três experimentos.

"O experimento do pH foi muito legal não sabia que o café e a coca cola tinham pH baixo sendo ácidos podendo provocar queimação." (E10).

"Não fazia ideia de como a química pode me fazer entender sobre o mal-estar da azia, e que o equilíbrio químico em nosso organismo se altera de acordo com a nossa alimentação". (E8).

"A escala de pH feita na aula ficou fácil de entender o comportamento ácido e base nos alimentos e no nosso organismo." (E4).

"A azia pode ser causada pela a má alimentação, ou seja, um pH ácido onde aumenta a quantidade de ácido no estomago e pode ser controlado pela reação de uma base ou um antiácido." (E9).

A experimentação proporcionou um novo olhar para as reações químicas. 0 conceito de reversibilidade é percebido pelos estudantes quando explicitam em seus 
textos: "O experimento do cobre azul perdeu a água e ficou cinza depois de aquecer e quando pingou água voltou a ficar azul acontecendo à reação reversível" (E1). O envolvimento do estudante a partir da linguagem do que já era conhecido rumo à construção de novos conceitos possibilitou que eles descrevessem e interpretassem o fenômeno.

[...] descrever é produzir proposições que enumerem propriedades, características, qualidades do fenômeno partindo do conhecimento que os estudantes que já têm sobre os temas das práticas, mantendo-se próximos dos contextos concretos em que a atividade se realiza. Ao interpretar é importante que o estudante consiga superar seus conhecimentos iniciais sobre os fenômenos, ações, possibilitada pela confrontação de autores (MORAES; RAMOS; GALIAZZI, 2007, p. 199).

De acordo com os recortes dos questionários e relatórios escritos pelos estudantes evidenciou-se a apropriação dos conhecimentos químicos, por meio da linguagem, da escrita e da experimentação.

Considerando aspectos observados durante as aulas como: participação oral e escrita, onde tencionaram suas ideias mediante a linguagem específica da química, desenvolvendo a escrita de textos e as respostas às questões propostas, leitura e discussão do tema proposto, afirmamos que a experimentação possibilitou a observação, a constatação e explicações para o fenômeno envolvendo o equilíbrio químico.

\section{CONSIDERAÇÕES FINAIS}

A sequência didática referente ao trabalho desenvolvido foi muito bem recebida pelos estudantes que participaram efetivamente das aulas expositivas e dialogadas e dos experimentos propostos. Assim, foi possível obter resultados positivos na receptividade dos estudantes para a continuidade das aulas dentro da temática proposta, pois consideraram as aulas prazerosas e com assunto pertinente ao seu cotidiano. 
Durante as aulas foram fomentados debates acerca das questões que envolviam alimentação e bem-estar, onde os estudantes assumiram o papel de protagonistas, sendo que seus conhecimentos e explicações foram importantes e considerados na dinâmica da sala de aula.

De acordo com o processo de ensino e aprendizagem que busca a problematização no e para o ensino de química, o professor deixa de ser um transmissor de saberes, e torna-se um mediador entre o estudante e o conhecimento, por outro lado, os estudantes se mostraram participativos, questionadores, reflexivos e sempre curiosos sobre o tema social apresentado.

Desta maneira, a partir do retorno dado pelos estudantes nos questionários, bem como suas intervenções e observações realizadas durante as aulas, confirmam que a aprendizagem aconteceu em diversos momentos na interação, questionamentos dos conteúdos que estavam sendo apresentados, nos momentos dos experimentos demonstrativos e até na resolução da lista de exercícios.

Essa dinâmica possibilitou aos estudantes pleitear sua participação não somente na construção dos conhecimentos, mas na sociedade, não mais como espectadores que acumulam conhecimentos, e sim como protagonistas de suas práticas sociais, tornando-os capazes de tomar decisões, de serem participativos e atuantes na sociedade; o "aprender" química está relacionado ao envolvimento em incursões para dentro dos discursos especializados dos químicos (MORAES; RAMOS; GALIAZZI, 2007). 


\section{REFERÊNCIAS}

CAChapuZ, A.; GIL-PEREZ, D.; CARVAlho, A. M. P. DE; PRAIA, J.; VILCHES, A. A necessária renovação do ensino das ciências. 2. ed. São Paulo: Cortez, 2011.

CHASSOT, A. Alfabetização científica: questões e desafios para a educação. 3. ed. Ijuí: 2003.

CHASSOT, A. Fazendo Educação em Ciências em um Curso de Pedagogia com Inclusão de Saberes Populares no Currículo. Química Nova na Escola, São Paulo, n. 27, p. 9-12, fev. 2008.

DELIZOICOV, D.; ANGOTTI, J. A. Metodologia do ensino de ciências. São Paulo, Cortez, 1990.

FREIRE, P. Pedagogia do Oprimido. 17. ed. Rio de Janeiro: Editora Paz e Terra, 1987.

FOUREZ, G; ROUANET, L. P.. A construção das ciências. São Paulo: Ed. Unesp, 1995.

GONÇALVES, S.; MOSQUERA, M. S.; SEGURA, A. F. La resolución de problemas em ciencias naturales: un modelo se enseñanza alternativo y superador. 1. ed. Buenos Aires: SB, 2007.

MORAES, R.; RAMOS, M. V. G.; GALIAZZI, M. do C. Aprender Química: promovendo excursões em discursos da Química. In: ZANON, L. B.; MALDANER, O. A. (Orgs) Fundamentos e Propostas de Ensino de Química para a Educação básica no Brasil, Ijuí: Ed. Unijuí, 2007.

PEREIRA, F. Contra a química, não há azia que resista. Em: <http://www1.folha.uol.com.br/fsp/fovest/fo0101200415.htm>. Acesso em 02 de novembro de 2015.

SANTOS, W. L. P.; MORTIMER, E. F. Tomada de decisão para ação social responsável no ensino de ciências. Ciência \& Educação, Bauru, v. 7, n. 1, p. 95-111, 2001. 
SCHNETZLER, R. P.; ARAGÃO, R. M. R. Importância, sentido e contribuições de pesquisas para o ensino de química. Química Nova na Escola, São Paulo, v. 1, p. 27-31, 1995.

SNYDERS, G. A Alegria na Escola. São Paulo: Paz Terra, 1988. 